\title{
Exposure to environmental tobacco smoke from husband more strongly impacts on the airway obstruction of nonsmoking women
}

This article was published in the following Dove Press journal: International Journal of COPD

\section{Kazuaki Suyama \\ Ryo Kozu \\ Takako Tanaka \\ Yuji Ishimatsu \\ Terumitsu Sawai}

Department of Cardiopulmonary Rehabilitation Science, Nagasaki University Graduate School of Biomedical Sciences, Nagasaki, Japan
Correspondence: Ryo Kozu Department of Cardiopulmonary Rehabilitation Science, Nagasaki University Graduate School of Biomedical Sciences, I-7-I Sakamoto, Nagasaki 852-8520, Japan

$\mathrm{Tel} / \mathrm{fax}+81958197963$

Email ryokozu@nagasaki-u.ac.jp
Background: The impact of airway obstruction of nonsmoking women caused by their husband's smoking is unclear, despite the association between environmental tobacco smoke (ETS) exposure at home and obstructive pulmonary diseases among nonsmoking women. The aim of this study was to provide evidence that ETS exposure from the husband at home has a more significant influence on the airway obstruction of nonsmoking women than other housemates.

Participants and methods: Nonsmoking women aged 40 years or older were recruited from the health checkup during May 2015-December 2016, Japan. They answered structured questionnaires, including ETS exposure from their husbands and other housemates (parents, siblings and dependants), and performed spirometry. We categorized the women with any history of ETS exposure from housemates into three groups $(\mathrm{A}=$ husband, $\mathrm{B}=$ others and $\mathrm{C}=$ both of husband and others) and defined the control group as those with no ETS exposure from housemates.

Results: A total of 811 nonsmoking women completed questionnaires and spirometry. The proportion of nonsmoking women who had airway obstruction (forced expiratory volume in 1 second $\left[\mathrm{FEV}_{1}\right] /$ forced vital capacity $\left.[\mathrm{FVC}]<70 \%\right)$ among Group A $(7.5 \%)$ was significantly higher than those in the control group $(1.1 \%, p<0.01)$ and Group $\mathrm{B}(0.8 \%, p<0.01)$. The proportion of airway obstruction in Group $\mathrm{C}(6.4 \%)$ was also higher than that in the control group $(p<0.05)$ and Group B $(p<0.05)$. ETS exposure from husband (odds ratio [OR], 3.53; 95\% confidence interval $[\mathrm{CI}], 1.48-8.42$ ) remained strongly associated with airway obstruction after multiple logistic regression analysis, adjusting for age, housemate's smoking habits, family history and ETS exposure in childhood and at work.

Conclusion: Nonsmoking women who were exposed to ETS from their husband had the lowest $\mathrm{FEV}_{\mathrm{l}} / \mathrm{FVC}$, and a higher proportion of them had airway obstruction when compared to nonsmoking women who experienced ETS from housemates other than their husbands. The findings suggest that tobacco control in husbands is the most important measure to prevent airway obstruction of nonsmoking women at home.

Keywords: environmental tobacco smoke, airway obstruction, nonsmoking women, husband, cross-sectional study

\section{Introduction}

The tobacco epidemic is a major public health problem impacting on global health. An estimated six million people die worldwide each year due to tobacco smoking. ${ }^{1}$ Exposure to environmental tobacco smoke (ETS) has been estimated to have caused 603,000 of the total 58.8 million deaths worldwide in $2004 .{ }^{2}$ Although the effects of tobacco smoking are broad and devastating, much smoking-related research has traditionally focused on the lung because the lung is considered to be the primary target 
organ affected. ETS exposure has been implicated as a cause of lung diseases such as lung cancer, ${ }^{3,4}$ asthma $^{5,6}$ and $\mathrm{COPD}^{7,8}$ among nonsmokers. In a recent systematic review and metaanalysis, it was also confirmed that the risk of developing these respiratory diseases caused by ETS exposure significantly increased. ${ }^{9}$

Within Japan, although the smoking rate has progressively declined since 1965 , it continues to be higher in men (29.7\%) than women (9.7\%). ${ }^{10}$ Thus, a significant number of Japanese women who are nonsmokers are exposed to the ETS at home as a result of males living at home who smoke. Specifically, ETS exposure at home has been associated with the development of obstructive lung diseases. ${ }^{7,11}$ In addition, husband's smoking is a significant risk factor for non-respiratory ETS-related diseases for the nonsmoking wife, such as coronary artery disease (CAD), ${ }^{12}$ stroke $^{13}$ and breast cancer. ${ }^{14}$

Although ETS exposure at home has been associated with the development of obstructive lung diseases according to some studies, ${ }^{7,11}$ these studies did not control for the effect of ETS exposure in childhood ${ }^{6,15,16}$ and/or the workplace..$^{717}$ In addition, there is no clarification on the effect of ETS exposure at home caused by all housemates' smoking on the airway obstruction of nonsmoking women. While it is important to focus on a husband's smoking status in the study of ETS-related diseases, ${ }^{12-14}$ to do so alone does not take into consideration other smokers at home. Thus, studies of the effects of ETS exposure on health outcomes should evaluate all potential sources of ETS exposure to reduce the risk of misclassification bias. ${ }^{18}$

We hypothesized that ETS exposure from the husband is more significantly associated with the airway obstruction of nonsmoking women at home than ETS exposure from other housemates. The aim of this study was to investigate the effect of ETS exposure on the presence of airway obstruction among nonsmoking women at home.

\section{Participants and methods Study design and setting}

This study was a community-based cross-sectional study of inhabitants in the three cities (Nagasaki, Ōmura and Matsuura) in Nagasaki Prefecture, Japan. Nonsmoking women aged 40 years or older were recruited from the health checkup held in the three cities between May 2015 and December 2016. This program is a voluntary health examination in which a battery of tests is conducted with the aim of early detection and treatment of disease. ${ }^{19}$ As part of this health checkup, we developed a system that aims to identify and treat COPD at an early stage..$^{20,21}$ This study was conducted with the approval of the human ethics review committee of Nagasaki University Graduate School of Biomedical Sciences (approval number 15111267). The participants' data were allocated a code to protect their identity, and all information was kept confidential. All participants provided written consent.

\section{Lung function tests}

Lung function tests were performed using a portable automatic calibrated spirometer (Autospiro AS-507 ${ }^{\circledR}$; Minato Medical Science, Osaka, Japan). The forced expiratory volume in 1 second $\left(\mathrm{FEV}_{1}\right)$ and forced vital capacity (FVC) were measured and used to derive $\mathrm{FEV}_{1} / \mathrm{FVC}$. Measurements were performed according to the American Thoracic Society (ATS) and European Respiratory Society (ERS) pulmonary function testing guidelines. ${ }^{22,23}$ For each participant, flowvolume loops were repeated until three reliable tracings were obtained, and the highest values were retained for analysis, in accordance with recommendations of the ATS/ERS. ${ }^{22}$ Reversibility testing with inhaled bronchodilators was not performed. A definition of airway obstruction was made when the $\mathrm{FEV}_{1} / \mathrm{FVC}$ value was $<70 \%$. $^{24}$

\section{ETS questionnaires and definitions}

Participants completed three questionnaires that were developed specifically for this study. The first two questionnaires were administered by an interviewer.

The first questionnaire comprised items to identify comorbidities associated with exposure to ETS (eg, cancers, diabetes, CAD), family history of COPD and asthma. The presence of respiratory symptoms (eg, cough, sputum, wheeze, allergies) was evaluated via the second questionnaire.

The third questionnaire contained questions about exposure to ETS at home and workplace. This questionnaire was self-administered to reduce misclassification caused by exposure suspicion bias. ${ }^{25,26}$ The questions included were: 1) "Has your husband ever smoked during the time he has lived with you?", "How often has he smoked?" and "Where has he smoked?"; 2) "Has a housemate other than your husband (eg, parents, siblings and dependants) ever smoked when living with you?", "How often has he/she smoked?" and "Where has he/she smoked?"; 3) "Have you ever been exposed to passive smoking in childhood?" and 4) "Have your coworkers ever smoked at work?" and "What is/was your occupation at that time?".

We classified participants into one of four groups according to ETS exposure at home (ie, whether housemates 
[husband and other housemates] were smokers). If the participant answered "Yes, currently" or "Yes, but not currently" in response to the first question of 1) only, they were categorized into Group A. If they answered "Yes, currently" or "Yes, but not currently" in response to the first question of 2) only, they were categorized into Group B. Individuals were categorized into Group C when they answered "Yes, currently" or "Yes, but not currently" in response to both questions 1) and 2). The control group comprised those who answered "No, never smoked" for both questions 1) and 2). In addition, the pack-years of the housemate's smoking habit were calculated as the product of the number of cigarettes per day and years of smoking during the time they lived with nonsmoking women. We also classified the location of smoking as either indoor (eg, living room, bedroom, dining and kitchen) or outdoor (eg, balcony and garden).

\section{Statistical analysis}

Data were assessed for normality using the Shapiro-Wilk test and visual inspection using frequency histograms. Differences in the characteristics of the nonsmoking women in each of the four comparison groups were assessed using the Tukey-Kramer test as a multiple comparison for continuous variables and chi-square tests for categorical variables. Adjusted odds ratios (ORs) and 95\% confidence intervals
(CIs) were calculated by multiple logistic regression adjusting for age, housemate's smoking habit and ETS exposure in childhood and at work. Statistical analysis was performed using IBM SPSS statistics version 23.0 for Windows (IBM Corporation, Armonk, NY, USA). Statistical significance was set at a probability of $<5 \%$.

\section{Results \\ Study population and characteristics}

During the study period, 857 nonsmoking women representing $52.5 \%$ of the total number of individuals who underwent the health checkup participated in this study (Figure 1). Of the 857 women, 811 (94.6\%) completed all questionnaires and lung function tests. Based on the questionnaire responses, the nonsmoking women were categorized into Group A $(n=308)$, Group B $(n=128)$, Group C $(n=188)$ or the control group $(n=187)$.

The characteristics of study participants are listed in Table 1. In all the groups that had exposure to ETS from housemates, the proportion of individuals with respiratory symptoms (cough and sputum) were higher than in the control group $(p<0.05)$. A significantly higher proportion of nonsmoking women who had a family history of COPD were found in Group A $(p<0.05)$ and Group C $(p<0.01)$ compared with the control group.

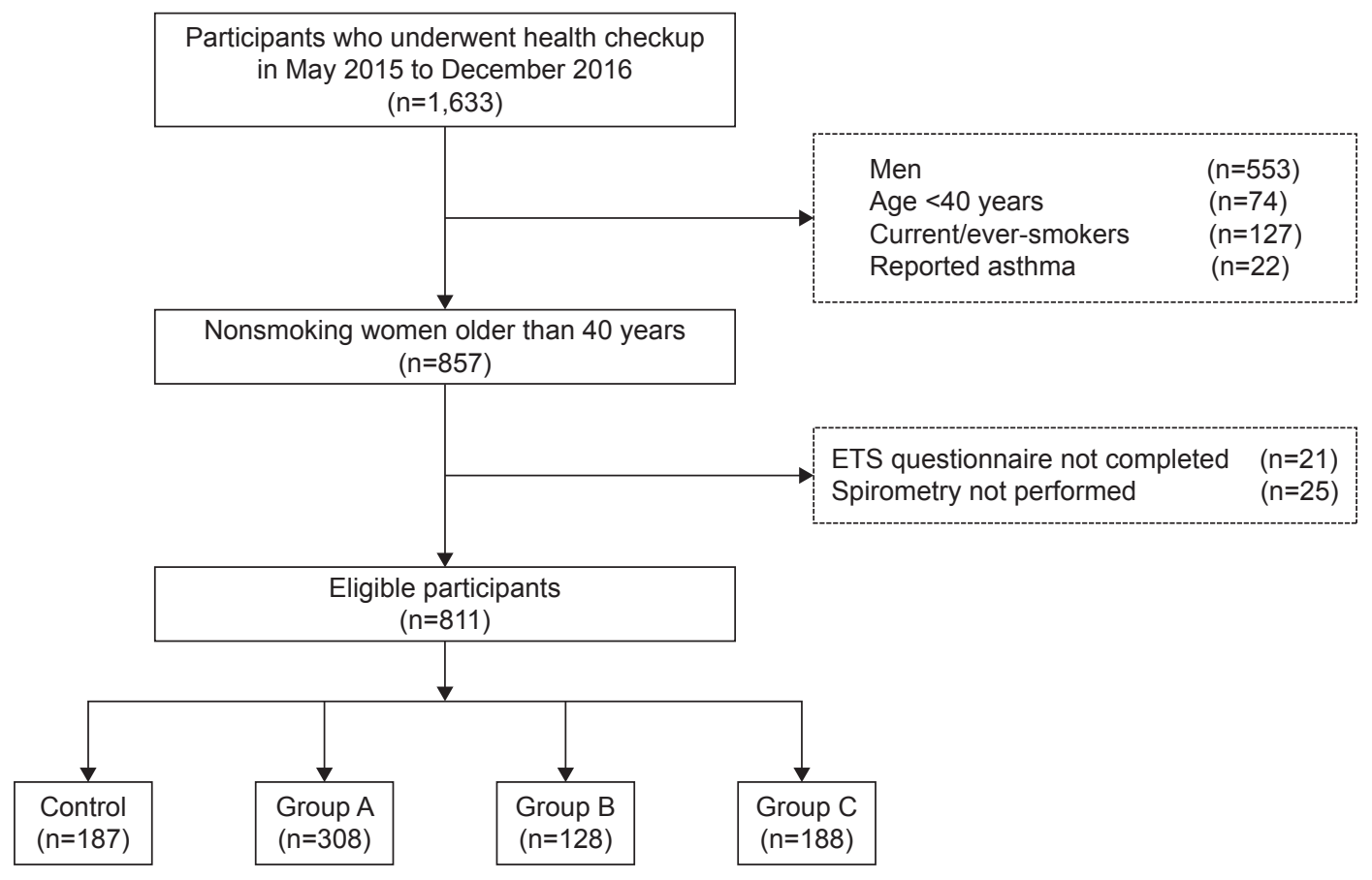

Figure I Flowchart of the study subjects who underwent health checkup.

Notes: Control was defined as without ETS exposure from any housemate. Group A included ETS exposure from husband only. Group B included ETS exposure from housemates other than husband. Group $C$ included ETS exposure from husband and other housemates.

Abbreviation: ETS, environmental tobacco smoke. 
Table I Characteristics of the study participants

\begin{tabular}{|c|c|c|c|c|}
\hline \multirow[t]{2}{*}{ Characteristics } & \multirow{2}{*}{$\begin{array}{l}\text { Control } \\
(n=\mid 87)\end{array}$} & \multicolumn{3}{|c|}{ ETS exposure from housemates } \\
\hline & & $\begin{array}{l}\text { Group A } \\
(n=308)\end{array}$ & $\begin{array}{l}\text { Group B } \\
(n=\mid 28)\end{array}$ & $\begin{array}{l}\text { Group C } \\
(n=188)\end{array}$ \\
\hline Age (years) & $65.8 \pm 10.9$ & $68.3 \pm 9.7 * *$ & $65.8 \pm 9.6$ & $66.1 \pm 11.0$ \\
\hline $\mathrm{BMI}$ & $22.3 \pm 3.4$ & $22.3 \pm 3.8$ & $22.5 \pm 3.4$ & $22.4 \pm 3.1$ \\
\hline \multicolumn{5}{|l|}{ Respiratory symptoms, n (\%) } \\
\hline Cough & $30(16.0)$ & $80(26.0)^{*}$ & $4 \mathrm{I}(32.0)^{* *}$ & $49(26.1)^{*}$ \\
\hline Sputum & $44(23.5)$ & $102(33.1)^{*}$ & $48(37.5)^{* *}$ & $54(28.7)^{*}$ \\
\hline Wheeze & $13(7.0)$ & $26(8.4)$ & $8(6.3)$ & $24(12.8)^{*}$ \\
\hline Allergies & $56(29.9)$ & $82(26.6)$ & $40(31.3)^{\dagger}$ & $52(27.7)$ \\
\hline \multicolumn{5}{|l|}{ Comorbidities, n (\%) } \\
\hline Cancers & $0(0.0)$ & $10(3.2)$ & $2(1.6)$ & $5(2.7)$ \\
\hline Diabetes & $7(3.7)$ & $18(5.8)$ & $7(5.5)$ & $8(4.3)$ \\
\hline CAD & $6(3.2)$ & $9(2.9)$ & $3(2.3)$ & $4(2.1)$ \\
\hline \multicolumn{5}{|l|}{ Family history, n (\%) } \\
\hline COPD & $9(4.8)$ & $34(1 \mathrm{I} .0)^{*}$ & $9(7.0)$ & $26(13.8)^{* *}$ \\
\hline Asthma & $14(7.5)$ & $33(10.7)$ & $16(12.5)$ & $25(13.3)^{*}$ \\
\hline \multicolumn{5}{|c|}{ Housemate's smoking habits during living period } \\
\hline Cigarettes/day & - & $19 \pm 10$ & $16 \pm 9$ & $20 \pm 10$ \\
\hline Smoking year & & $28 \pm 14^{\ddagger}$ & $21 \pm 13$ & $27 \pm 14^{\ddagger}$ \\
\hline Pack-years & - & $44 \pm 33^{\text {㧊 }}$ & $31 \pm 43$ & $44 \pm 33^{\text {㧊 }}$ \\
\hline Indoor/outdoor & & $207 / 101$ & $92 / 36^{+\dagger}$ & $158 / 30^{t+t}$ \\
\hline ETS exposure in childhood, $n(\%)$ & - & $152(49.4)$ & $83(64.8)^{\dagger \dagger}$ & $138(73.4)^{\dagger+\dagger}$ \\
\hline \multicolumn{5}{|l|}{ ETS exposure at work, $n$} \\
\hline Current/former/never & $15 / 66 / 106$ & $26 / 134 / 148^{*}$ & $|6 / 5| / 6 \mid$ & $34 / 78 / 76$ ** \\
\hline Office/laborer/service/farm/other & $27 / 4 / 24 / 1 / 25$ & $60 / 8 / 43 / 5 / 44$ & $28 / 4 / 20 / 2 / 13$ & $34 / 6 / 35 / 3 / 34$ \\
\hline
\end{tabular}

Notes: Data are represented as mean \pm standard deviation or number (\%). *Vs control, $p<0.05$; **vs control, $p<0.01$; ${ }^{\dagger}$ vs Group A, $p<0.05$; ${ }^{\dagger}$ vs Group A, $p<0.0$ I; ${ }^{t+t}$ vs Group A, $p<0.001$; ‡vs Group B, $p<0.05$; ${ }^{\ddagger}$ vs Group B, $p<0.01$. Control was defined as without ETS exposure from any housemate. Group A included ETS exposure from husband only. Group B included ETS exposure from housemates other than husband. Group C included ETS exposure from husband and other housemates.

Abbreviations: ETS, environmental tobacco smoke; BMI, body mass index; CAD, coronary artery disease.

\section{Condition of ETS exposure}

The housemates of the participants in both Group A and Group $\mathrm{C}$ had smoked for more years than the housemates of those in Group B (both $p<0.05$; Table 1). Furthermore, there was a significant difference in pack-years between Group A $(p<0.01)$ and Group C $(p<0.01)$ compared with Group B. We also demonstrated that pack-years was not significantly different between Group A and Group C. Compared with the control group, there was a higher rate of ETS exposure at work among Group A $(p<0.05)$ and Group C $(p<0.01)$.

\section{Lung function and airway obstruction}

The results of the lung function tests in nonsmoking women grouped according to ETS exposure are given in Table 2.

Table 2 Comparison of lung function in nonsmoking women grouped according to ETS exposure

\begin{tabular}{|c|c|c|c|c|}
\hline \multirow[t]{2}{*}{ Characteristics } & \multirow{2}{*}{$\begin{array}{l}\text { Control } \\
(n=187)\end{array}$} & \multicolumn{3}{|c|}{ ETS exposure from housemates } \\
\hline & & $\begin{array}{l}\text { Group A } \\
(n=308)\end{array}$ & $\begin{array}{l}\text { Group B } \\
(n=128)\end{array}$ & $\begin{array}{l}\text { Group C } \\
(n=188)\end{array}$ \\
\hline \multicolumn{5}{|l|}{ FVC } \\
\hline L & $2.29(1.93-2.59)$ & $2.28(1.98-2.58)$ & $2.36(2.03-2.61)$ & $2.32(2.05-2.66)$ \\
\hline$\%$ predicted & $95(86-105)$ & $98(88-109)$ & $97(90-106)$ & $98(89-109)$ \\
\hline \multicolumn{5}{|l|}{$\mathrm{FEV}_{1}$} \\
\hline L & $1.90(1.59-2.17)$ & $1.78(1.53-2.04)$ & $1.93(1.62-2.17)$ & $1.82(1.59-2.07)$ \\
\hline$\%$ predicted & $98(89-108)$ & $96(86-107)$ & $98(89-109)$ & $95(86-105)$ \\
\hline $\mathrm{FEV}_{\mathrm{I}} / \mathrm{FVC}, \%$ & $82(79-86)$ & $77(74-8 \mathrm{I}) * * *,+t \dagger$ & $82(78-84)^{* *}$ & $79(75-8 \mathrm{I})^{* * *,+\dagger}$ \\
\hline $\mathrm{FEV}_{\mathrm{I}} / \mathrm{FVC}<70 \%, \%$ & I.I & $7.5^{* *,+\dagger}$ & 0.8 & $6.4^{*, \dagger}$ \\
\hline
\end{tabular}

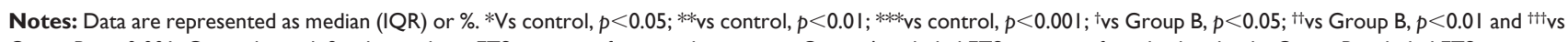
Group B, $p<0.00$ I. Control was defined as without ETS exposure from any housemate. Group A included ETS exposure from husband only. Group B included ETS exposure from housemates other than husband. Group $C$ included ETS exposure from husband and other housemates.

Abbreviations: ETS, environmental tobacco smoke; FVC, forced vital capacity; FEV , forced expiratory volume in I second; IQR, interquartile range; L, liter. 
Table 3 Multiple logistic regression analysis of airway obstruction among nonsmoking women

\begin{tabular}{|c|c|c|c|c|}
\hline \multirow{2}{*}{$\begin{array}{l}\text { ETS exposure } \\
\text { from housemates }\end{array}$} & \multicolumn{2}{|c|}{ Crude } & \multicolumn{2}{|c|}{ Adjusted $^{\mathrm{a}}$} \\
\hline & OR & $95 \% \mathrm{Cl}$ & OR & $95 \% \mathrm{Cl}$ \\
\hline Husband & $4.04^{\S \S \S}$ & $1.83-8.93$ & $3.53^{\S \S}$ & I.48-8.42 \\
\hline Parents & 1.53 & $0.73-3.23$ & $2.43^{\S}$ & I.02-5.75 \\
\hline Siblings & 0.65 & $0.09-4.87$ & 0.60 & $0.08-4.62$ \\
\hline Dependants & 0.32 & $0.08-1.37$ & 0.22 & $0.05-1.00$ \\
\hline
\end{tabular}

Notes: aAdjusted for age, housemate's smoking habits, family history of asthma COPD, ETS exposure in childhood and ETS exposure at work. ${ }^{s} p<0.05,{ }^{s s} p<0.01$ and ${ }^{558} p<0.001$.

Abbreviations: $\mathrm{ETS}$, environmental tobacco smoke; OR, odds ratio; $\mathrm{Cl}$, confidence interval.

$\mathrm{FEV}_{1} / \mathrm{FVC}$ was significantly lower in the nonsmoking women assigned to the three groups with ETS exposure from housemates compared with the control group $(p<0.01$ and $p<0.001$, respectively). Specifically, Group A had a lower $\mathrm{FEV}_{1} / \mathrm{FVC}$ than Group B (77\% vs $82 \%$, respectively; $p<0.001)$. Furthermore, compared with Group B $(0.8 \%)$, a higher proportion of individuals with airway obstruction in Group A $(7.5 \%, p<0.01)$ and Group C $(6.4 \%, p<0.05)$ were observed.

\section{Impact of ETS exposure from housemates}

The results of the multiple logistic regression analysis are given in Table 3. The crude OR for ETS exposure from husband was significantly associated with airway obstruction (OR, 4.04; 95\% CI, 1.83-8.93). This also remained the highest risk factor for airway obstruction after adjusting for age, housemate's smoking habits, family history of asthma/ COPD, ETS exposure in childhood and ETS exposure at work (adjusted OR, 3.53; 95\% CI, 1.48-8.42). ETS exposure from parents was shown to be the second highest risk factor for airway obstruction after ETS exposure from husband (adjusted OR, 2.43; 95\% CI, 1.02-5.75). ETS exposure from siblings and dependants was not a significant risk factor for airway obstruction among nonsmoking women.

\section{Discussion}

We demonstrated that nonsmoking women who were exposed to the ETS from their housemates experienced respiratory symptoms and demonstrated the presence of airway obstruction. In particular, nonsmoking women who were exposed to ETS from their husband had the lowest $\mathrm{FEV}_{1} / \mathrm{FVC}$, and this had the highest OR for airway obstruction after adjusting for confounding factors.

To our knowledge, this is the first study to examine the effects of ETS exposure from all housemates with a smoking history. In addition, we demonstrated that exposure to ETS from the husband had the strongest impact on the airway obstruction of nonsmoking women at home in comparison to other ETS-related risks, that is, ETS exposure in childhood ${ }^{6,15,16}$ and at the workplace., ${ }^{717}$ These results suggest that controlling the tobacco smoking of the husband at home is the most important strategy to prevent the development of airway obstruction in their nonsmoking wife.

In our study groups that were exposed to ETS from housemates, there was a significantly higher proportion of people with respiratory symptoms and lower $\mathrm{FEV}_{1} / \mathrm{FVC}$ than those in the control group. More respiratory symptoms and lower lung function have been reported when there are high levels of tobacco in the house as measured by high levels of particulate matter. ${ }^{11,27}$ Therefore, our results using data obtained via questionnaires are consistent with these previous reports that measured particulate matter.

A novel finding of this study is that nonsmoking women who had long-term exposure to ETS from their husband had a lower $\mathrm{FEV}_{1} / \mathrm{FVC}$ than women who were exposed to ETS from other housemates. Moreover, exposure from the husband was associated with the highest OR for airway obstruction compared to that from other housemates. Maziak et $\mathrm{al}^{28}$ derived an ETS score using self-report data, respiratory symptoms and lung function among 1,118 nonsmokers and found dose-response relationships of ETS exposure with symptoms of asthma/bronchitis and airway obstruction. The dose-response relationships of ETS exposure were also found with both the intensity (ie, number of cigarettes) and amount (ie, pack-years of exposure) of the husbands' smoking among nonsmoking women who were diagnosed with lung cancer. ${ }^{29}$ That is, it was suggested that the higher pack-years of smoking attributed to the husband had a greater effect on the development of airway obstruction in nonsmoking women in our study, as a result of living with the husband for a long term. Indeed, the smoking rate of Japanese men in the 1970s and $1980 \mathrm{~s}$, this being the time when the nonsmoking women in our study are likely to have married, was $\sim 80 \% .{ }^{10}$ Previous studies on Japanese nonsmoking women and ETS exposure have been focused on husbands' smoking because there was a high smoking rate among the Japanese men. ${ }^{14,29}$ Therefore, the finding that many nonsmoking women belonged to the ETS group of husbands with higher pack-years can be inferred from the traditional smoking habits of husbands. Our study also showed that ETS exposure from the husband was more associated with airway obstruction than ETS exposure from parents. While it is well known that parental smoking is a significant ETS risk factor for obstructive pulmonary diseases, ${ }^{9}, 15,16$ our study suggests that a husband's smoking is an independent risk factor of airway obstruction compared 
with parent's smoking. Incidentally, although there was some variation in the sample size between the husband's ETS group and the other ETS groups, the influence would be less because we pre-confirmed the homoscedasticity of each group (data not shown).

Limitations of this study include selection bias because individuals could choose whether or not to participate in the health checkup. In addition, reversibility testing was not undertaken, thus limiting the diagnosis of airway obstruction. However, it was reported that environmental factors including smoking are an important common risk factor for obstructive pulmonary diseases such as asthma and COPD. ${ }^{30}$ Thus, in this study that was aimed at identifying airway obstruction associated with exposure to ETS, it was not very important to diagnose obstructive pulmonary disease. Another limitation is the likelihood of recall bias in response to questions about ETS exposure and the lack of reliable precise quantitative data on the exposure from housemates. Specifically, since the timings of exposure of nonsmoking women differ between the husband and other housemates, differences in recall accuracy may have occurred. Finally, we did not assess other potential exposal factors such as public space (eg, restaurant or bar $^{31}$ ), which might influence results.

\section{Conclusion}

Nonsmoking women who were exposed to ETS from their husbands had the lowest $\mathrm{FEV}_{1} / \mathrm{FVC}$, and a higher proportion of them had airway obstruction when compared to nonsmoking women who experienced ETS from housemates other than their husbands. Our study provides the evidence that exposure of ETS from the husband has the strongest impact on the airway obstruction of nonsmoking women than ETS from all housemates. Moreover, it suggests that tobacco control in husbands is the most important measure to prevent the development of airway obstruction in nonsmoking women at home.

\section{Acknowledgments}

We thank the study participants; the staff of the Government of Matsuura District, Nagasaki Prefecture; Nagasaki City Medical Association, Nagasaki City Office and coworkers for their help. In addition, we are grateful to Dr Sue Jenkins, Institute for Respiratory Health and Physiotherapy Department, Sir Charles Gairdner Hospital, for her help in reviewing our manuscript. Furthermore, we appreciate the extensive support of Dr Hironori Masaki, Masaki Respiratory Clinic, on the management of health checkup. Finally, we thank Prof Sumihisa Honda, Department of Community-based Rehabilitation Sciences, Nagasaki University Graduate School of Biomedical Sciences, for his support on the statistical analysis of this study.

\section{Author contributions}

RK was the principal investigator and contributed to the design of the study, supervised the team's work and made critical revisions to the paper for intellectual content. KS designed the study; drafted and revised, collected, analyzed and interpreted the data and prepared the paper. RK interpreted the data, analyzed the data, handled supervision and made critical revisions to the paper for important intellectual content. YI and TS contributed toward data analysis and made critical revisions to the paper for important intellectual content. TT collected and interpreted the data, drafted the manuscript and made critical revisions to the paper for important intellectual content. All authors contributed toward data analysis, drafting and revising the paper and agree to be accountable for all aspects of the work.

\section{Disclosure}

The authors report no conflicts of interest in this work.

\section{References}

1. World Health Organization. WHO Report on the Global Tobacco Epidemic 2013, Enforcing Bans on Tobacco Advertising, Promotion and Sponsorship. Geneva: World Health Organization; 2013.

2. Öberg M, Jaakkola MS, Woodward A, Peruga A, Prüss-Ustün A. Worldwide burden of disease from exposure to second-hand smoke: a retrospective analysis of data from 192 countries. Lancet. 2011;377(9760): 139-146.

3. Hirayama T. Non-smoking wives of heavy smokers have a higher risk of lung cancer: a study from Japan. Br Med J (Clin Res Ed). 1981; 282(6259):183-185.

4. Hori M, Tanaka H, Wakai K, Sasazuki S, Katanoda K. Secondhand smoke exposure and risk of lung cancer in Japan: a systematic review and meta-analysis of epidemiologic studies. Jpn J Clin Oncol. 2016;46(10): 942-951.

5. Jerzynska J, Stelmach I, Grzelewski T, Stelmach W, Krakowiak J. High exposure to passive tobacco smoking and the development of asthma in an adult patient who had never smoked. Am J Respir Crit Care Med. 2010;182(3):433-434.

6. Coogan PF, Castro-Webb N, Yu J, O'Connor GT, Palmer JR, Rosenberg L. Active and passive smoking and the incidence of asthma in the Black Women's Health Study. Am J Respir Crit Care Med. 2015;191(2): 168-176.

7. Hagstad S, Bjerg A, Ekerljung L, et al. Passive smoking exposure is associated with increased risk of COPD in never smokers. Chest. 2014; 145(6): 1298-1304.

8. Tan WC, Sin DD, Bourbeau J, et al. Characteristics of COPD in neversmokers and ever-smokers in the general population: results from the CanCOLD study. Thorax. 2015;70(9):822-829.

9. Jayes L, Haslam PL, Gratziou CG, et al. SmokeHaz: systematic reviews and meta-analyses of the effects of smoking on respiratory health. Chest. 2016;150(1):164-179.

10. Japan Health Promotion \& Fitness Foundation [webpage on the Internet]. Smoking Rate in Adults. 2016. Available from: http://www.health-net. or.jp/tobacco/product/pd090000.html. Accessed February 28, 2017. 
11. Balmes JR, Cisternas M, Quinlan PJ, et al. Annual average ambient particulate matter exposure estimates, measured home particulate matter, and hair nicotine are associated with respiratory outcomes in adults with asthma. Environ Res. 2014;129:1-10.

12. He Y, Lam TH, Li LS, et al. The number of stenotic coronary arteries and passive smoking exposure from husband in lifelong non-smoking women in Xi'an, China. Atherosclerosis. 1996;127(2):229-238.

13. Zhang X, Shu XO, Yang G, et al. Association of passive smoking by husbands with prevalence of stroke among Chinese women nonsmokers. Am J Epidemiol. 2005;161(3):213-218.

14. Wada K, Kawachi T, Hori A, et al. Husband's smoking status and breast cancer risk in Japan: from the Takayama study. Cancer Sci. 2015;106(4): 455-460.

15. Lovasi GS, Diez Roux AV, Hoffman EA, Kawut SM, Jacobs DR, Barr RG. Association of environmental tobacco smoke exposure in childhood with early emphysema in adulthood among nonsmokers: the MESA-lung study. Am J Epidemiol. 2010;171(1):54-62.

16. Johannessen ANE, Bakke PS, Hardie JA, Eagan TML. Association of exposure to environmental tobacco smoke in childhood with chronic obstructive pulmonary disease and respiratory symptoms in adults. Respirology. 2012;17(3):499-505.

17. Nguyen KH, King BA, Dube SR. Association between current asthma and secondhand smoke exposure in vehicles among adults living in four US states. Tob Control. 2015;24(4):376-381.

18. Edwards R. Spousal smoking as an indicator of total secondhand smoke exposure. Nicotine Tob Res. 2009;11(6):606-613.

19. Oike T, Senjyu H, Higa N, et al. Detection of airflow limitation using the 11-Q and pulmonary function tests. Intern Med. 2013;52(8): 887-893.

20. Tawara Y, Senjyu H, Tanaka K, et al. Value of systematic intervention for chronic obstructive pulmonary disease in a regional Japanese city based on case detection rate and medical cost. Int J Chron Obstruct Pulmon Dis. 2015;10:1531-1542.
21. Asai M, Tanaka T, Kozu R, Kitagawa C, Tabusadani M, Senjyu H Effect of a chronic obstructive pulmonary disease (COPD) intervention on COPD awareness in a regional city in Japan. Intern Med. 2015;54(2): 163-169.

22. Miller MR, Hankinson J, Brusasco V, et al. Standardisation of spirometry. Eur Respir J. 2005;26(2):319-338.

23. Pellegrino R, Viegi G, Brusasco V, et al. Interpretative strategies for lung function tests. Eur Respir J. 2005;26(5):948-968.

24. Global Initiative for Chronic Obstructive Lung Disease [webpage on the Internet]. GOLD Spirometry Guide. Available from: http://goldcopd. org/gold-spirometry-guide/. Accessed May 20, 2017.

25. Lee PN, Forey BA. Misclassification of smoking habits as a source of bias in the study of environmental tobacco smoke and lung cancer. Stat Med. 1996;15(6):581-605.

26. $\mathrm{Wu} \mathrm{AH}$. Exposure misclassification bias in studies of environmental tobacco smoke and lung cancer. Environ Health Perspect. 1999; 107(suppl 6):873-877.

27. Hulin M, Simoni M, Viegi G, Annesi-Maesano I. Respiratory health and indoor air pollutants based on quantitative exposure assessments Eur Respir J. 2012;40(4):1033-1045.

28. Maziak W, Ward KD, Rastam S, Mzayek F, Eissenberg T. Extent of exposure to environmental tobacco smoke (ETS) and its dose-response relation to respiratory health among adults. Respir Res. 2005;6:13.

29. Kurahashi N, Inoue M, Liu Y, et al. Passive smoking and lung cancer in Japanese non-smoking women: a prospective study. Int J Cancer. 2008;122(3):653-657.

30. Postma DS, Kerkhof M, Boezen HM, Koppelman GH. Asthma and chronic obstructive pulmonary disease: common genes, common environments? Am J Respir Crit Care Med. 2011;183(12):1588-1594.

31. Flouris AD, Metsios GS, Carrillo AE, et al. Acute and short-term effects of secondhand smoke on lung function and cytokine production. Am J Respir Crit Care Med. 2009;179(11):1029-1033.
International Journal of COPD

\section{Publish your work in this journal}

The International Journal of COPD is an international, peer-reviewed journal of therapeutics and pharmacology focusing on concise rapid reporting of clinical studies and reviews in COPD. Special focus is given to the pathophysiological processes underlying the disease, intervention programs, patient focused education, and self management protocols.

\section{Dovepress}

This journal is indexed on PubMed Central, MedLine and CAS. The manuscript management system is completely online and includes a very quick and fair peer-review system, which is all easy to use. Visit http://www.dovepress.com/testimonials.php to read real quotes from published authors. 